\title{
The elderly and implications of their biopsychosocial needs for health care in Latin America
}

\begin{abstract}
Objective: To analyze the experience of caring for the elderly using the biopsychosocial approach, based on the scientific evidence, in order to strengthen health care in Latin America.

Method: An integrative review of original and systemic review articles, published between 2014 and 2019. The search was conducted using MEDLINE (Produced in the National Library of Medicine of the United States), LILACS (Latin American Literature and of the Caribbean in Health Sciences), CUMED (Cuban Medical Literature), and BDENF (Virtual Health Library in Nursing). Search descriptors included: older adult, and needs assessment. Fifteen articles were identified that met the inclusion criteria.
\end{abstract}

Results: The main health needs of the elderly population correspond to problems related to specific pathologies and health problems. The Psychological and social needs arise from living alone, social isolation, recent functional dependence, low social interaction, depression in old age, management of the physical or social environment, changes in sexual relationships, abuse and neglect.

Conclusions: The needs biopsychosocial can be supported with general health education relevant to older adults; such education needs to focus on the specific needs and life experience of each elderly person

Keywords: elderly person, needs assessment, aging, older adults, sociodemographic changes
Volume 4 Issue 6 - 2019

\author{
Ángela Cristina Yánez,' María Patricia \\ Masalan Apip, ${ }^{2}$ Gerald L Kellogg ${ }^{3}$ \\ 'Nurse, Professor at the Faculty of Nursing of the Pontifical \\ Catholic University of Ecuador, Doctor in Nursing from the \\ Universidad Andrés Bello de Chile, Chile \\ ${ }^{2}$ Nurse, Master in Public Health, Associate Professor School of \\ Nursing, Pontificia Universidad Católica de Chile, Chile \\ ${ }^{3}$ Instructional Designer, Master in Education. Adult education \\ expert, Chile
}

Correspondence: Ángela Cristina Yánez, Nurse, Professor at the Faculty of Nursing of the Pontifical Catholic University of Ecuador, Doctor in Nursing from the Universidad Andrés Bello de Chile, Chile, Tel +593983913894, Email acyanz.co@gmail.com

Received: October 28, 2019 | Published: November 06, 2019
Abbreviations: MEDLINE, produced in the national library of medicine of the united states; LILACS, latin american and caribbean literature in health sciences; CUMED, cuban medical literature, CGAGOLD, comprehensive geriatric assessment

\section{Introduction}

The elderly population is growing worldwide. In 2017 there were 962 million people over 60 years old, and according to projections for 2050, it is expected to double to 2100 million. Europe in 2017 registered the highest percentage of the population aged 60 or over (25\%) compared to the rest of the world. In that same year in Latin America there were 77 million older adults. According to the data, the pace of aging in developing countries is faster than in developed countries. Therefore, Latin America will have less time to adapt to the consequences of population aging, which include dependence on other people, socio-economic impact, and multiple manifestations and consequences of the aging process. ${ }^{1}$

The extension of life expectancy offers opportunities, not only for older adults and their families, but also for developing societies. In these additional years of life, seniors can undertake new activities, continue studies, start a new profession, develop new skills or hobbies, and contribute in some way to the extended family environment. All this depends on health factors and available opportunities. To guarantee these opportunities, WHO has determined five priority areas of action: 1) Commitment to healthy aging, which requires sensitivity to generate policies for the benefit of the elderly; 2) Alignment of health systems with the needs of the elderly; 3) Establishment of systems to provide chronic disease care; 4) Creation of environments adapted to the elderly; and 5) Improvement of measurements, monitoring and understanding, which encourages research on aspects that contribute to the care of the elderly individuals. ${ }^{2}$

Taking into account these areas, and considering that the Latin American population requires dynamic bases of action for demographic transformation, this integrative review will investigate the following question: What are the biological, psychological and social health needs of older adults, based on our experience of caring for the elderly, so that we can provide adequate health management for this population? Therefore, the objective of this review is to analyze the experience of caring for the elderly under the biopsychosocial approach, based on the scientific evidence.

\section{Methodology}

A bibliographic search was carried out in the following databases: MEDLINE (Produced in the National Library of Medicine of the United States), LILACS (Latin American and Caribbean Literature in Health Sciences), CUMED (Cuban Medical Literature), BDENF (Library virtual health in Nursing). The search descriptors used were: Older person, needs assessment, and evaluation of needs DECS/ MESH in English, Spanish, Portuguese, from the Virtual Health Library (BIREME). The article selection criteria included 1) systemic reviews and original articles, 2) availability of full text, 3) texts in all the indicated languages and 4) publications between 2014 and 2019. 
The search yielded a total of 625 articles from which 61 were selected, classifying them according to: 1) biological needs, 2) psychological needs and 3) social needs. They are presented individually and grouped according to the health needs of similar older adults (Figure $1)$.

The analysis of the health needs of older adults was organized by taking into account one of the priority areas of action of the WHO's "Alignment of Health Systems with the Needs of the Elderly", organizing evidence from biological, psychological and social needs of the elderly. This strategy was used in order to establish guidelines for health care, with actions related to promotion, prevention, cure, treatment, home care and health rehabilitation.

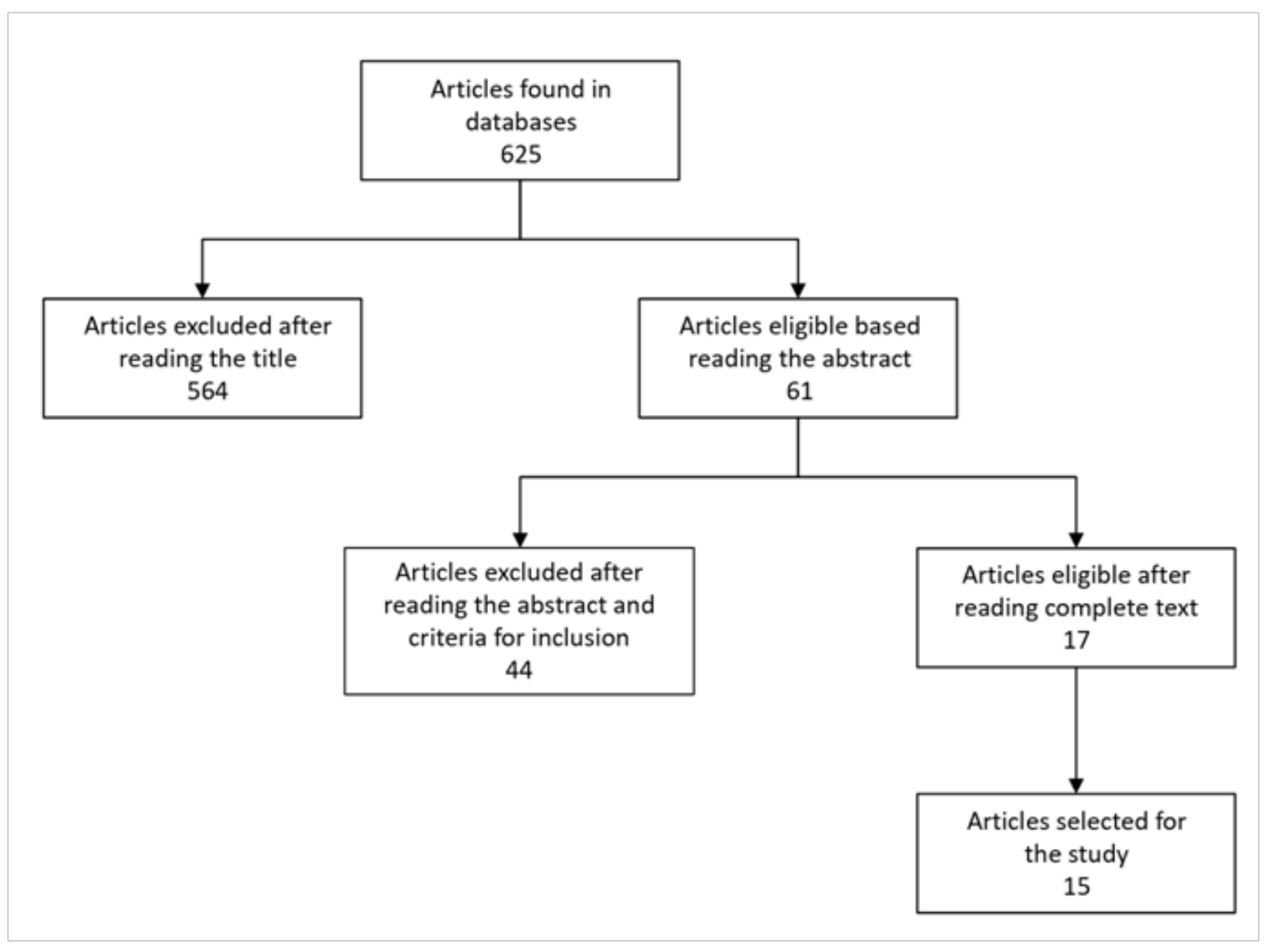

Figure I Flowchart of the selection process of the articles included in the review. 2019.

\section{Results}

\section{Biological health needs}

In the biological field, a large part of research on the elderly focuses on specific pathologies, their management and the adaptation process. At present, this vision represents a reductionist approach since it does not consider perceived biological health needs as determined by older adults, caregivers or health professionals.

In the review of the literature, the approach to the biological needs of the elderly today varies widely. For example, one of the major problems cited is the need for managing urinary incontinence, which can interfere with the activities of daily living in the elderly (ADL). ${ }^{3}$

On the other hand, the application of the Balance of Care $(\mathrm{BoC})$ model as a way to explore the provision of resources and services in the community and in social and health institutions reveals high levels of need for managing dementia and stroke. ${ }^{4-10}$

The Comprehensive Geriatric Assessment (CGA-GOLD) questionnaire, when used to detect co morbidity based on evidence and quality of life (EORTC-QLQ-C30), reveals multi-faceted approach problems such as hypertension, diabetes, dyspnea on flat surfaces, polypharmacy, difficulty walking, fatigue, urinary incontinence and falls. ${ }^{11,12}$

Other studies identify the needs of the elderly in terms of satisfaction and dissatisfaction. In the biological domain, dissatisfaction is significantly associated with depression. In addition to the impaired functional state, vision, hearing, sleep and exercise, it is striking that for these needs the risk factors of age, institutionalization and care by family members are elements that contribute to the satisfaction of needs. ${ }^{13,17}$ 
In the nutritional area, a longitudinal survey on aging determined that nutritional status is in urgent need of attention, and it suggests that the application of anthropometric indicators focused on the measurement of calf circumference (CC) shows better results than the calculation of the Body Mass Index (BMI). Likewise, the risk of malnutrition is evident in older adults who have been recently admitted to large health care institutions. ${ }^{18-20}$

In the field of palliative care, the evaluation of five triggers is suggested: 1) hospital stay greater than or equal to 10 days; 2) multisystem organ failure greater than or equal to three systems; 3 ) stage IV malignancy; 4) post-cardiac arrest status; and 5) intracerebral hemorrhage that requires mechanical ventilation. ${ }^{21}$

\section{Psychological and social health needs}

Regarding psychological and social needs, studies show that living alone, social isolation, recent functional dependence, and low social interaction are the ones that determine the highest prevalence. ${ }^{12-14}$

In studies conducted through the application of AgeMooDe, a prospective observational study, "Depression in old age in primary care: needs, use of medical care and costs", argues that more research on medical use and costs for the older person is required. ${ }^{12-22}$

Studies also suggest that the quality of life, health conditions and life expectancy of the elderly person is related to adverse childhood experiences (ACE); that is to say that the adverse events that occur in the first years of life generate an emotional imbalance affecting the personal resources the older adult can draw on later in life..$^{15,23}$

Alternatively, an analysis of the environmental management needs of the elderly is considered by some studies to be crucial in improving their quality of life. Analyses of the environments of older adults are integral to the field of environmental gerontology, which emphasizes the need for an interdisciplinary approach to understanding the attributes and functions of the physical-social environment in the aging population, which ultimately contributes to planning gerontological care with a holistic perspective. ${ }^{24}$

Other studies demonstrate the need to approach intimate relationships and sexuality, from the analysis of physical changes that modify the sexual response, to emphasizing the gender differences in intimate situations. For example, age-related in skin and mucous membranes more serious for women because their mucous membranes are less extensible. For men, however, the use of certain medications can impair circulation, particular the vascular line, causing difficulties in erection and ejaculation, often leading to a sense of failure. Neurological and hormonal changes, different perceptions of cold and heat, and alteration of each person's hourly rhythms suggest the need for a change in sexual activity which focuses more on direct stimulation for both men and women and constituting a cultural conflict for Latin American women. ${ }^{15,25-35}$

Some studies suggest that abuse, neglect and mistreatment of the elderly are prevalent, and appropriate measures to prevent them are lacking. These abuses may be physical, sexual, psychological or emotional in nature. Interventions are needed to prevent and address violence for economic or material reasons, abandonment or negligence, and serious loss of dignity among the elderly. ${ }^{35,36}$

Finally, a study analyzes the need of the elderly person to live in a community that emphasizes important themes such as "family is central" or "church is central", "heritage", "unity", "strength" and "longevity". Conversely, community leaders perceive the "rural economy", "distance to resources" and "seasonal resources" as significant barriers for older adults who need to develop. ${ }^{37}$ Findings such as these reveal new challenges for health services in the framework of care for the elderly.

\section{Discussion}

Faced with the sociodemographic changes raised, it is necessary to propose actions aimed at responding to the emerging needs of the elderly that involves each component of the system -- people, families and communities -- and thus make available the resources that allow these possible solutions to implemented.

Based on the WHO's five priority areas of action which focus on the "alignment of health systems with the needs of the elderly", it is worth asking 1) to what extent unsatisfied needs related to impaired functional status, vision, hearing, sleep and exercise can be met in a timely and efficient manner and 2) what actions the health team's should take to satisfy them. Behind these needs lies the quality of life of the elderly person, which according to research, is best addressed through cognitive behavioral interventions the improvement of sleep quality, for example, is one such need. ${ }^{14,17}$

Although there are numerous studies of interventions in the elderly population group, there are no data on the use and cost of medical care in Latin America. Service providers currently invest in meeting the needs of an economically active population, including workers and their families, and are unprepared for the increasing care demands of an aging population. In Latin American, this phenomenon requires increased attention, and forces us to rethink the organization of services to cover unmet needs and prepare professionals to confront these needs. ${ }^{38,39}$

Regarding gender-related needs, the available evidence does not show a differentiation of biological or psychosocial needs by gender. However, the bibliography suggests that Latin America women have a longer life expectancy than men, although it does not appear to be related to better life conditions. In Latin American culture, most women assume a traditionally female domestic role, with the associated physical labor, making them more vulnerable to the lack of resources and institutional protection. ${ }^{40-42}$

On the other hand, there is no evidence of greater interventions with older males. The differences in traditional male and female roles makes it difficult for older men to be included in the educational or social programs that involve mixed groups. This suggests the needs for gender-specific health care practices for the elderly.

As long as the objective of such care is to improve the quality of life of the elderly person, health care personnel will need to be trained in educational psychology in order to achieve care goals. ${ }^{43-45}$

\section{Conclusion}

The main health needs of the elderly population correspond to problems related to specific pathologies such as urinary incontinence, hypertension, diabetes, dyspnea on flat surfaces; health problems such as polypharmacy, difficulty walking, fatigue, falls, impaired functional status, problems with vision, hearing, sleep, exercise, nutritional aspect; and triggers for palliative care such as hospital stays, multisystemic organ failure, post-cardiac arrest status and intracerebral hemorrhage that requires mechanical ventilation. Psychological and social needs arise from living alone, social isolation, recent functional dependence, 
low social interaction, depression in old age, management of the physical or social environment, changes in sexual relationships, abuse and neglect. While many of these needs can be supported with general health education relevant to older adults, such education needs to focus on the specific needs and life experience of each elderly person.

\section{Acknowledgements}

None.

\section{Conflict of interests}

Authors declare that there is no conflict of interest

\section{References}

1. Viveros Madariaga A. Aging and old age in latin america and the caribbean: public policies and the actions of society [Internet]. 22nd ed. Chile: CEPAL; 2001.

2. https://www.who.int/es/news-room/fact-sheets/detail/envejecimiento-ysalud

3. Yang E, Lisha N, Walter L, et al. Urinary Incontinence in a national cohort of older women: implications for caregiving and care dependence. Journal of Women's Health. 2018;27(9):1097-1103.

4. Tanuseputro P, Hsu A, Kuluski K, et al. Level of need, divertibility, and outcomes of newly admitted nursing home residents. journal of the american medical directors association. 2017;18(7):616-623.

5. Joenperä J. Tales from the ACFI: Dementia in residential aged care. Australasian Journal on Ageing. 2017;36(1):10-13.

6. Risco E, Zabalegui A, Miguel S, et al. Application of the Balance of Care model in decision-making regarding the best care for patients with dementia. Gaceta Sanitaria. 2017;31(6):518-523.

7. Tucker S, Brand C, Wilberforce M, et al. The balance of care approach to health and social care planning: Lessons from a systematic literature review. Health Services Management Research. 2013;26(1):18-28.

8. Tucker S, Hughes J, Burns A, et al. The balance of care: reconfiguring services for older people with mental health problems. Aging \& Mental Health. 2008;12(1):81-91.

9. Tucker S, Hughes J, Jolley D, et al. Reconfiguring in-patient services for adults with mental health problems: changing the balance of care. BJPsych Open. 2018;4(6):420-426.

10. Risco E, Zabalegui A, Miguel S, et al. Aplicación del modelo balance of care en la toma de decisiones acerca del mejor cuidado para las personas con demencia. Gaceta Sanitaria. 2017;31(6):518-523.

11. Whittle A, Kalsi T, Babic-Illman G, et al. A comprehensive geriatric assessment screening questionnaire (CGA-GOLD) for older people undergoing treatment for cancer. European Journal of Cancer Care. 2016;26(5): e12509.

12. Hsu W, Chen L, Wang J. Predicting emerging care-need with simple functional indicators: Findings from a national cohort study in Taiwan. Geriatrics \& Gerontology International. 2016;17(3):375-381.

13. Somerville E, Smallfield S, Stark S, et al. Occupational therapy home modification assessment and intervention. American Journal of Occupational Therapy. 2016;70(5):7005395010p1.

14. Stein J, Pabst A, Weyerer S, et al. The assessment of met and unmet care needs in the oldest old with and without depression using the camberwell assessment of need for the elderly (CANE): results of the agemoode study. Journal of Affective Disorders. 2016;193:309-317.

15. Stein J, Luppa M, König H, et al. The german version of the camberwell assessment of need for the elderly (cane): evaluation of content validity and adaptation to the german-speaking context. International Psychogeriatrics. 2015;27(11):1919-1926.

16. Bowen K, Gonzalez E, Edwards C, et al. Needs assessments of memory disorder patients. American Journal of Alzheimer's Disease \& Other Dementiasr. 2014;29(8):667-672.

17. Domínguez-Guedea M. Social Challenges of Aging: reflection from the right to development. CES Psicología. 2016;9(1):150-164.

18. Pezzana A, Cereda E, Avagnina P, et al. Nutritional care needs in elderly residents of long-term care institutions: Potential implications for policies. The journal of nutrition, health \& aging. 2015;19(9):947-954.

19. Pezzana A, Cereda E, Avagnina P, et al. PP221-SUN: nutritional care needs in long-term care elderly residents. Clinical Nutrition. 2014;33:S102.

20. Hsu W, Tsai A, Wang J. Calf circumference is more effective than body mass index in predicting emerging care-need of older adults - Results of a national cohort study. Clinical Nutrition. 2016;35(3):735-740.

21. Hua M, Li G, Blinderman C, et al. Estimates of the need for palliative care consultation across united states intensive care units using a triggerbased model. American Journal of Respiratory and Critical Care Medicine. 2014;189(4):428-436.

22. Bock J, Brettschneider C, Weyerer S, et al. Excess health care costs of late-life depression - results of the agemoode study. Journal of Affective Disorders. 2016; 199:139-147.

23. Del Águila-Escobedo Aníbal. Violence and child stress: is our future at stake?Acta méd. peruana . 2015;32(2):71-83.

24. Salinas-Miranda A, Salemi J, King L, et al. Adverse childhood experiences and health-related quality of life in adulthood: revelations from a community needs assessment. Health and Quality of Life Outcomes. 2015;13(1).

25. Sánchez González D. Physical-social environment and aging of the population from environmental gerontology and geography: Sociospatial implications in Latin America. Revista de geografia Norte Grande. 2015;(60):97-114.

26. Baeza Correa J. Sexualidad en adultos mayores. Medwave. 2007;7(6).

27. Monteiro A, von Humboldt S, Leal I. How do formal caregivers experience the sexuality of older adults? Beliefs and attitudes towards older adults' sexuality. Psychology, Community \& Health. 2017;6(1):7792.

28. Guillermina S, Keydis R, Sindy J, et al. Sexuality in elderly adults: study on knowledge and attitudes related to sexuality in older adults. Global Journal of Health Science. 2019;11(7):184.

29. Quevedo León L. Importancia de la sexualidad en el adulto mayor. Cultura del cuidado. 2013;10(2):70-79.

30. Jiang, L. Sexuality and romantic relationships among older adults. The Gerontologist. 2016;56(Suppl 3):523-523.

31. Natividad Sologuren G, Linares Torres C. Vivencia de la sexualidad en el adulto mayor - Tacna 2016. Revista Médica Basadrina. 2019;11(1):3036.

32. González Domínguez RA, Núñez Rodríguez LM, Hernández Pupo O, et al. Sexualidad en el adulto mayor. Mitos y realidades. Archivo Médico Camagüey. 2015;9(4).

33. Rosales Rodríguez Reinalda de la C, García Diaz Reina de La Caridad, et al. Lifestyle and self-perception on mental health in the elderly. Medisan. 2014;18(1):61-67.

34. Díaz Alfonso Humbelina, Lemus Fajardo Nora María, Álvarez Oscar. La sexualidad en un grupo de ancianos que asisten a consulta de Urología. Rev Ciencias Médicas. 2015;19(4):667-677. 
35. Ruelas-González M, Pelcastre-Villafuerte B, Reyes-Morales H Maltrato institucional hacia el adulto mayor: percepciones del prestador de servicios de salud y de los ancianos. Salud Pública de México. 2014;56(6):631.

36. García Rosique Regla Mercedes, Guisado Zamora Katia, et al. Maltrato intrafamiliar hacia el adulto mayor en el del policlínico reynold garcía de versalles. Rev Med Electrón. 2016;38(6):826-836.

37. Goris E, Schutte D, Rivard J, Schutte B. Community leader perceptions of the health needs of older adults. Western Journal of Nursing Research. 2014;37(5):599-618.

38. Carmona-Valdés S. Factors that influence the health condition of the elderly in poverty in Nuevo León, Mexico. Población y Salud en Mesoamérica. 2015;13(2).

39. De los Santos P, Carmona Valdés S. Prevalence of depression in older men and women in Mexico and risk factors. Población y Salud en Mesoamérica. 2017;15(2).
40. Suaya D. El cuerpo de la vejez desde una perspectiva de género. Aproximaciones desde La vejez de Simone de Beauvoir. Cadernos cedes. 2015;35(97):617-627.

41. Sánchez Guzmán M. Género Y Vejez: una mirada distinta a un problema común. Ciencia. 2011;1(1):1-6.

42. Suay A. Envejecimiento y desigualdad de género- Geriatricarea Geriatricarea. 2019.

43. Psicólogos C. Daily routines in the elderly: what do they do what they would like to do?. Infocop es. 2019.

44. Jara P. Tres razones por las que ser hombre o ser mujer en la vejez importa. Gente Saludable. 2019.

45. Masalan AMP, Río CMP, Del Yánez C, et al. Cognitive-behavioral intervention on senior adults with sleep disorders. Enferm univ. $2018 ; 15(1): 6-16$ 